\title{
Enhanced stability of passivation quality on diffused silicon surfaces under light-induced degradation conditions
}

\author{
David Sperber*, Anton Schwarz, Axel Herguth, Giso Hahn \\ Department of Physics, University of Konstanz, Universitätsstr. 10, 78464 Konstanz, Germany
}

\section{A R T I C L E I N F O}

\section{Keywords:}

Light induced degradation

Surface related degradation

Surface passivation

Diffused silicon

Silicon nitride

Aluminium oxide

\begin{abstract}
A B S T R A C T
Significant surface related degradation (SRD) is observed in samples passivated with either $\mathrm{SiN}_{\mathrm{x}}: \mathrm{H}$ or $\mathrm{AlO}_{\mathrm{x}}: \mathrm{H}$ / $\mathrm{SiN}_{\mathrm{x}}: \mathrm{H}$ during treatment at $150{ }^{\circ} \mathrm{C}$ and 1 sun equivalent illumination intensity. Degradation of $\mathrm{SiN}_{\mathrm{x}}: \mathrm{H}$ passivation is caused by a decrease of chemical passivation quality whereas degradation of $\mathrm{AlO}_{\mathrm{x}}: \mathrm{H} / \mathrm{SiN}_{\mathrm{x}}: \mathrm{H}$ is caused by a decrease of fixed charge density. SRD is, however, strongly suppressed on highly doped silicon surfaces resulting from a diffusion step. Device simulations indicate that this cannot only be explained by reduced sensitivity to changes at the silicon surface due to the diffused region, and implications for defect formation are discussed.
\end{abstract}

\section{Introduction}

Different types of light induced degradation (LID) can significantly decrease the bulk minority carrier lifetime $\tau_{\mathrm{b}}$ in crystalline silicon, which directly translates to a lower efficiency of affected silicon solar cells. Examples are Light and elevated Temperature Induced Degradation (LeTID) [1-5] and boron-oxygen (BO) related LID [6-8]. Recently, it has been observed that surface passivation on crystalline silicon [9] may degrade as well after prolonged treatment under typical LID conditions [10-12]. Accordingly, degradation may occur both in the bulk and at the surface of a sample during LID experiments, making the interpretation of measurement data challenging [12].

So far, it has been shown that single layers of $\mathrm{SiN}_{\mathrm{x}}: \mathrm{H}$ as well as layer stacks consisting of $\mathrm{SiO}_{\mathrm{x}} / \mathrm{SiN}_{\mathrm{x}}: \mathrm{H}$ and $\mathrm{AlO}_{\mathrm{x}}: \mathrm{H} / \mathrm{SiN}_{\mathrm{x}}: \mathrm{H}$ can be affected by surface related degradation (SRD). Since the latter two are used as rearside passivation in passivated emitter and rear cell concepts (PERC) [13-15] and SRD was observed even at $60^{\circ} \mathrm{C}$ and 0.1 suns in lifetime samples, it appears possible that finished PERC cells could be affected in the long term as well [12]. However, SRD has so far only been observed on lowly doped silicon. In this contribution, it will be shown that degradation of surface passivation quality is strongly suppressed on diffused silicon surfaces. Potential reasons for this observation will be discussed on the basis of device simulations.

\section{Material and methods}

\subsection{Sample processing}

Lifetime samples were made of either boron-doped float-zone silicon (FZ-Si) with doping density $\mathrm{N}_{\mathrm{d}} \approx 1.5 \cdot 10^{16} \mathrm{~cm}^{-3}$ or phosphorousdoped FZ-Si with $\mathrm{N}_{\mathrm{d}} \approx 2 \cdot 10^{15} \mathrm{~cm}^{-3}$. The wafers received a saw damage etch, chemical cleaning and chemical polish by the manufacturer and were shipped with a thickness of $250 \mu \mathrm{m}$ and a thin surface oxide layer. This layer was removed by a dip in diluted HF. Further sample processing and sample labeling are illustrated in Fig. 1.

One B-doped wafer received a diffusion in $\mathrm{POCl}_{3}$ ambient at $840{ }^{\circ} \mathrm{C}$, resulting in a heavily P-doped $\mathrm{n}^{+}$emitter with sheet resistance $\sim 55 \Omega$ / sq. After removal of the phosphosilicate glass in diluted HF, the emitter was etched back (EEB) to $\sim 120 \Omega$ /sq. using an aqueous solution of $\mathrm{HF}$, $\mathrm{HNO}_{3}$ and $\mathrm{NaNO}_{2}[16,17]$. On other samples, heavily B-doped $\mathrm{p}^{+}$ layers were formed in $\mathrm{BBr}_{3}$ ambient at a drive-in temperature of $910^{\circ} \mathrm{C}$, resulting in a sheet resistance $\sim 100 \Omega$ sq. The surface of diffused samples was then oxidized in a solution of $\mathrm{H}_{2} \mathrm{O}_{2}$ and $\mathrm{H}_{2} \mathrm{SO}_{4}$ at $80^{\circ} \mathrm{C}$, followed by a dip in diluted $\mathrm{HF}$ to remove impurities from the sample surface (Piranha clean). The resulting doping profiles were measured via Electrochemical Capacitance-Voltage (ECV) profiling and are shown in Fig. 2. Additional wafers received no diffusion step to serve as reference samples.

The P-diffused and a reference wafer were coated with $\sim 75 \mathrm{~nm}$ $\mathrm{SiN}_{\mathrm{x}}: \mathrm{H}$ in a direct plasma-enhanced chemical vapor deposition (PECVD) at $40 \mathrm{kHz}$. B-diffused wafers and references were coated with $\sim 10 \mathrm{~nm}$

\footnotetext{
* Corresponding author.

E-mail addresses: david.sperber@uni-konstanz.de (D. Sperber), anton.schwarz@uni-konstanz.de (A. Schwarz), axel.herguth@uni-konstanz.de (A. Herguth), giso.hahn@uni-konstanz.de (G. Hahn).
} 


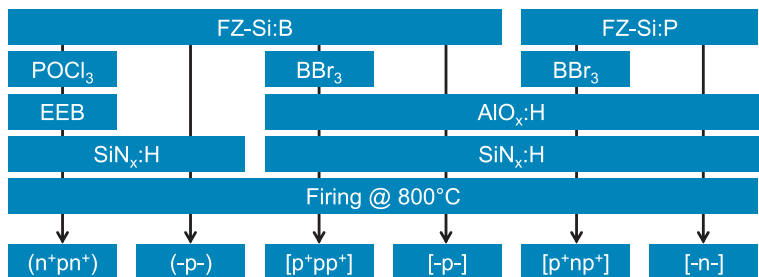

Fig. 1. Process flow and labeling of samples. Sample names indicate the sample structure and different brackets relate to different dielectric passivation layers.

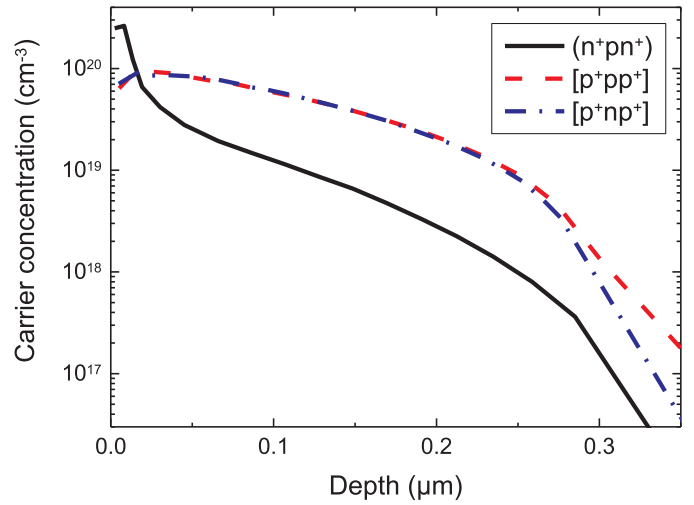

Fig. 2. Depth-resolved carrier concentrations measured via ECV profiling. In case of the $\left(\mathrm{n}^{+} \mathrm{pn}^{+}\right)$sample, the emitter was already etched back to $\sim 120 \Omega /$ sq. before ECV profiling.

$\mathrm{AlO}_{\mathrm{x}}: \mathrm{H}$ grown by plasma assisted atomic layer deposition (PA-ALD) and capped with $\sim 75 \mathrm{~nm}$ of $\mathrm{SiN}_{\mathrm{x}}: \mathrm{H}$ deposited in a remote plasma PECVD at $2.45 \mathrm{GHz}$. The refractive index of the $\mathrm{SiN}_{\mathrm{x}}: \mathrm{H}$ layers was in both cases $\sim 2.0$ at $600 \mathrm{~nm}$ and all layers were deposited symmetrically on both wafer sides. Finally, all samples were laser-cut to $5 \mathrm{~cm}$ edge length, fired in a fast firing belt furnace at measured peak sample temperature $(800 \pm 10)^{\circ} \mathrm{C}$, and stored in darkness until sample treatment started.

\subsection{Sample treatment and analysis}

Samples were treated in ambient air on hotplates at $150{ }^{\circ} \mathrm{C}$ and $(0.9 \pm 0.1)$ sun equivalent halogen lamp illumination which was achieved by matching the short circuit current of a solar cell to that under a solar spectrum simulator [18]. Sample treatment was repeatedly interrupted to measure the effective lifetime $\tau_{\text {eff }}$ using the generalized mode [19] of a Sinton Instruments lifetime tester (WCT120) [20] at $30^{\circ} \mathrm{C}$.

To quantitatively compare SRD, surface related saturation current

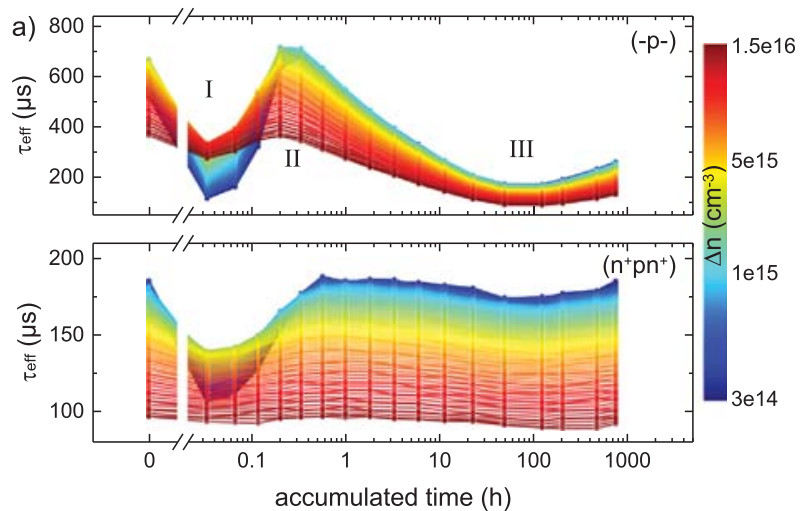

densities $J_{0}$ are determined from measured $\tau_{\text {eff }}$ according to the method described by Kimmerle et al. [21]. The excess charge carrier density $\Delta n$ (also called "injection level") for the fit of $J_{0}$ ranges from $8 \cdot 10^{15}$ to $1.5 \cdot 10^{16} \mathrm{~cm}^{-3}$ for B-doped samples and from $6 \cdot 10^{15}$ to $1.2 \cdot 10^{16} \mathrm{~cm}^{-3}$ for P-doped samples. Values of $J_{0}$ are calculated with respect to the effective intrinsic carrier concentration $n_{i e}=\sqrt{p_{0} n_{0}}$ at $25^{\circ} \mathrm{C}$ where $p_{0}$ is the equilibrium hole concentration and $n_{0}$ the equilibrium electron concentration in the bulk. The uncertainty of $\tau_{\text {eff }}$ in a transient PCD measurement is $\sim 8 \%[22,23]$. To estimate an uncertainty of $J_{0}$ values, input values of $\tau_{\text {eff }}$ were therefore varied by $\pm 8 \%$ and the resulting variation in $J_{0}(\sim 8 \%$ as well) constitutes one part of its uncertainty. It is furthermore possible that data are not strictly linear in the region of the $J_{0}$ fit which forms an additional source of uncertainty. For example, strong bulk recombination can have a residual influence even after correction measures as described in [21], leading to a slight curvature in data to fit. To account for this uncertainty, data were additionally fitted only in the lower or upper part of their fit ranges and the resulting difference in $J_{0}$, being a measure of data curvature, was weighted such that a residual influence of known bulk degradation (minimum I in Fig. 3) was covered by the total uncertainty.

In case of diffused samples, the resulting $J_{0}$ equals the emitter saturation current density $J_{0 \mathrm{e}}$. For non-diffused samples, $J_{0}$ equals the surface saturation current density $J_{0 s}[24]$ under the assumption that surface related recombination happens at the silicon surface only and can therefore be described with a surface recombination velocity $S$. For strong band bending due to high fixed charge density $Q_{\mathrm{f}}$ of dielectric layers, the following relationship holds [24]:

$J_{0 \mathrm{~s}}=q S \frac{2 k T \epsilon_{\mathrm{Si}}}{Q_{f}^{2}} n_{\mathrm{is}}^{2} \approx q S \frac{2 k T \epsilon_{\mathrm{Si}}}{Q_{f}^{2}} n_{\mathrm{ie}}^{2}$

with the effective intrinsic carrier concentration $n_{\text {is }}$ at the sample surface and $n_{\text {ie }}$ in the bulk which differ only marginally in non-diffused samples. Here and in the following, $S$ equals the surface recombination velocity of electrons $S_{\mathrm{n} 0}$ when electrons are minority carriers at the surface and it equals the surface recombination velocity of holes $S_{\mathrm{p} 0}$ when holes are the minority species.

After treatment, selected samples were wet-chemically re-passivated using iodine ethanol (IE). To achieve this, dielectric layers were removed in diluted HF. Afterwards, $\sim 4 \mu \mathrm{m}$ were removed on both samples sides in a solution of acetic acid, $\mathrm{HNO}_{3}$ and HF. Samples then received two Piranha cleans and were passivated using a $0.08 \mathrm{M}$ iodine in ethanol solution [25-28]. To exclude outliers, $J_{0}$ fit ranges had to be slightly adjusted for IE passivated samples.

Selected samples were additionally analyzed at different points of treatment with corona charging (CC) series and capacitance-voltage (CV) measurements on both sample sides. CC can compensate the field effect passivation by deposition of charges of opposite sign compared to $Q_{\mathrm{f}}$ of a dielectric layer. The minimal lifetime reached during a CC series

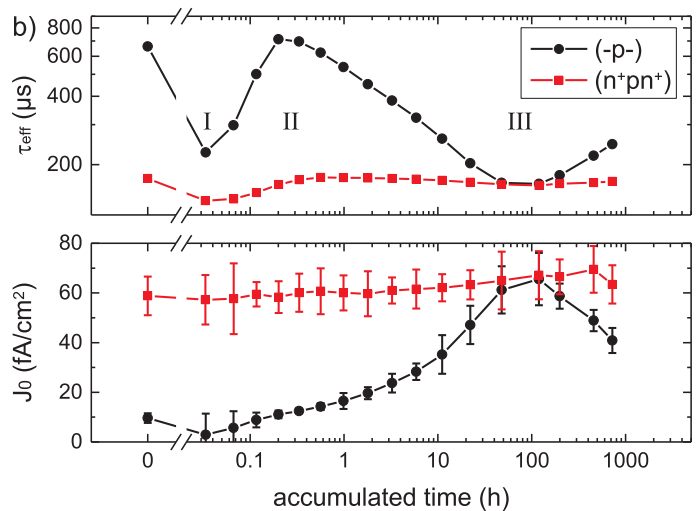

Fig. 3. (a) Injection resolved measurement of $\tau_{\text {eff }}$ of B-doped samples with and without P-emitter during treatment at $150{ }^{\circ} \mathrm{C}$ and $\sim 1$ sun equivalent illumination (color online). (b) Measurement of $\tau_{\text {eff }}\left(\Delta n=0.1 N_{\mathrm{d}}\right)$ and calculated values of $J_{0}$ of the same samples. 
is, therefore, a measure of chemical passivation quality. After a CC series on one sample side, the charge was removed from the sample surface with a dip in deionized water. CV measurements, on the other hand, were used to determine the density of fixed charges $Q_{f}$. Both types of measurements and experimental procedures are described in more detail in [11]. The measurements were applied consecutively on both sample sides to check whether SRD affects only the illuminated front or both front and rear side of a sample.

\section{Results}

\subsection{SiN $_{x}: H$ passivated samples}

Fig. 3(a) shows measurement data of B-doped samples with and without $\mathrm{P}$-emitter. In both cases, $\mathrm{SiN}_{\mathrm{x}}: \mathrm{H}$ was used as passivation layer. $\tau_{\text {eff }}$ is shown color-coded in dependence of $\Delta n$ as introduced in [29]. A first minimum "I" in the reference sample without emitter (-p-) is especially pronounced at lower injection (blue) and arises due to degradation and regeneration of bulk lifetime $\tau_{\mathrm{b}}$ [11,30-32]. Another minimum "III" after prolonged sample treatment is characterized by lower $\tau_{\text {eff }}$ at higher injection (red) and occurs due to degradation and recovery of chemical passivation quality $[11,12]$.

The $\left(\mathrm{n}^{+} \mathrm{pn}^{+}\right)$sample with emitter generally features lower lifetimes, especially at higher injection, due to additional recombination in the emitter region. Still, the bulk related minimum I can be clearly identified. After regeneration of $\tau_{\mathrm{b}}$, however, the sample appears to be very stable. Only a very slight dip in lifetime is visible after around $\sim 100 \mathrm{~h}$ of sample treatment. This dip occurs in temporal accordance with minimum III of the sample without emitter.

As can be seen, in case of the sample without emitter a dip occurs in $J_{0}$ as well during bulk degradation (minimum I, Fig. 3(b), black data). The large uncertainty of $J_{0}$ values at this point arises due to strong curvature of data to fit and indicates that this dip is very likely related to a residual influence of strong bulk recombination at minimum I on the determination of $J_{0}$ even after applying correction terms as described in [21] and does not indicate a real change of $J_{0}$. Before treatment and after bulk regeneration, uncertainties of $J_{0}$ are rather low and $J_{0}$ shows a strong long-term increase of $\sim 55 \mathrm{fA} / \mathrm{cm}^{2}$ after $\sim 100 \mathrm{~h}$ in good agreement with the surface related minimum III of $\tau_{\text {eff. }} J_{0}$ of the sample with emitter (red data) is, on the other hand, rather stable and shows only a slight increase of $\sim 8 \mathrm{fA} / \mathrm{cm}^{2}$ after $\sim 100 \mathrm{~h}$ of sample treatment.

Results from CC and CV measurements shown in Table 1 indicate clearly that (-p-) samples mainly suffer from degradation and regeneration of chemical passivation quality (lower values of $\tau_{\text {eff }}$ after CC) while the charge remains rather constant, in good agreement with results presented in [11]. Additionally, it can be seen that the decrease in chemical passivation quality affects both the illuminated front and dark rear side in a very similar manner which implies that SRD of (-p-) samples is not a direct effect of illumination (which would only affect the front side). As it was furthermore observed that SRD is accelerated at $150{ }^{\circ} \mathrm{C}$ under illumination compared to darkness [10], SRD is assumed to be a subtype of carrier induced degradation (CID).

\section{Table 1}

$\tau_{\text {eff }}$ before $\left(\tau_{\text {noCC }}\right)$ and after $\left(\tau_{\mathrm{CC}}\right)$ corona charging of front or rear side of (-p-) samples as well as measured $Q_{\mathrm{f}}$ before ("Initial") and after ("Final") LID treatment. Initial values were measured on an untreated (-p-) sample; final values were measured at the end of treatment of the (-p-) sample shown in Fig. 3.

\begin{tabular}{llllll}
\hline Sample & Side & $\begin{array}{l}\text { Initial } \tau_{\mathrm{CC}} \\
\left(\tau_{\text {noCC }}\right)[\mu \mathrm{s}]\end{array}$ & $\begin{array}{l}\text { Final } \tau_{\mathrm{CC}} \\
\left(\tau_{\text {noCC }}\right)[\mu \mathrm{s}]\end{array}$ & $\begin{array}{l}\text { Initial } Q_{\mathrm{f}}[\mathrm{q} / \\
\left.\mathrm{cm}^{2}\right]\end{array}$ & $\begin{array}{l}\text { Final } Q_{\mathrm{f}}[\mathrm{q} / \\
\left.\mathrm{cm}^{2}\right]\end{array}$ \\
\hline$(-\mathrm{p}-)$ & Front & $84(590)$ & $19(230)$ & $+3.0 \cdot 10^{12}$ & $+2.5 \cdot 10^{12}$ \\
$(-\mathrm{p}-)$ & Rear & $88(590)$ & $20(230)$ & $+3.4 \cdot 10^{12}$ & $+3.5 \cdot 10^{12}$ \\
\hline
\end{tabular}

\section{2. $A \mathrm{AO}_{x}: \mathrm{H} / \mathrm{SiN}_{x}: \mathrm{H}$ passivated samples}

In Fig. 4, P-doped samples with and without B-emitter are shown. Both samples are passivated with an $\mathrm{AlO}_{\mathrm{x}}: \mathrm{H} / \mathrm{SiN}_{\mathrm{x}}: \mathrm{H}$ stack. As can be seen, $\tau_{\text {eff }}$ of the sample without emitter [-n-] shows a significant rise already after $2 \mathrm{~min}$ of treatment. Because $J_{0}$ does not decrease in this timeframe, it is assumed that this first rise is associated with changes in the Si bulk. Starting at $\sim 5 \mathrm{~h}$, the sample shows a long-term degradation during which $\tau_{\text {eff }}$ is most limited at higher injection levels (red) and $J_{0}$ values rise. In addition, $\tau_{\text {eff }}$ is significantly increased and $J_{0}$ decreased after wet-chemical re-passivation after sample treatment (boxes denoted with "IE" in Fig. 4b). It is concluded that this sample suffers from significant SRD.

The $\left[\mathrm{p}^{+} \mathrm{np}^{+}\right]$sample shows neither the initial rise nor the long-term decline of $\tau_{\text {eff }}$, and $J_{0}$ values increase by no more than $3 \mathrm{fA} / \mathrm{cm}^{2}$ during sample treatment which lies within the measurement uncertainty. Interestingly, values of $J_{0}$ are surpassed by those of the sample without emitter after around $100 \mathrm{~h}$, indicating better surface passivation in the sample with emitter. Indeed, values of $\tau_{\text {eff }}$ reach $\sim 2 \mathrm{~ms}$ at $\Delta n=0.5 N_{\mathrm{d}}$ in the $\left[\mathrm{p}^{+} \mathrm{np}^{+}\right]$sample while degrading to $\sim 1.2 \mathrm{~ms}$ in the [-n-] sample, indicating that the emitter offers a stable high level of passivation quality as implied by the low $J_{0}$ values.

However, a strong decrease of $\tau_{\text {eff }}$ towards lower injection can be observed which probably results from edge-related recombination as described in $[33,34]:$ In a $\left[\mathrm{p}^{+} \mathrm{np}^{+}\right]$sample there are transport channels to the non-passivated sample edges for both electrons and holes. For samples with high $\tau_{\text {eff }}$ such edge-related recombination can exert an effect up to several centimeters away from the sample edges. Indeed, photoluminescence imaging shows a very strong edge-related effect which increases in width with decreasing generation similar to observations in [33] (data not shown). It is thus concluded that the low injection limitation of the $\left[\mathrm{p}^{+} \mathrm{np}^{+}\right]$sample arises due to edge-related recombination and a better passivated edge or larger samples would very likely reach much higher $\tau_{\text {eff }}$ at lower injection levels.

To check for a potential limitation of $\tau_{\mathrm{b}}$ after treatment, the $\mathrm{p}^{+}$ layers of the $\left[\mathrm{p}^{+} \mathrm{np}^{+}\right]$sample were etched off and the sample was repassivated with iodine ethanol as described in Section 2. Afterwards, it features similar $J_{0}$ but higher $\tau_{\text {eff }}$, especially at lower injection. This is a consequence of the removal of the $\mathrm{p}^{+}$layers during the etch process before IE passivation which prevents edge-related recombination (additionally, the edges are now passivated with IE, too). A higher $J_{0}$ after IE passivation in the $\left[\mathrm{p}^{+} \mathrm{np}^{+}\right]$compared to the [-p-] sample probably arises due to variations in IE passivation quality.

Fig. 5 shows B-doped samples with and without B-diffused layer coated with $\mathrm{AlO}_{\mathrm{x}}: \mathrm{H} / \mathrm{SiN}_{\mathrm{x}}: \mathrm{H}$. Similar to the sample with $\mathrm{SiN}_{\mathrm{x}}: \mathrm{H}$ passivation (-p-) in Fig. 3, the reference sample with $\mathrm{AlO}_{\mathrm{x}}: \mathrm{H} / \mathrm{SiN}_{\mathrm{x}}: \mathrm{H}$ passivation [-p-] first shows a degradation and regeneration of $\tau_{\mathrm{b}}$ leading to minimum I. Afterwards, $\tau_{\text {eff }}$ increases until a maximum II is reached after $\sim 20 \mathrm{~h}$ of treatment before $\tau_{\text {eff }}$ decreases again and is most limited at higher injection levels, making SRD the likely cause of degradation. However, $J_{0}$ is not rising significantly during the long-term degradation and even starts to decrease at $\sim 200 \mathrm{~h}$ while $\tau_{\text {eff }}$ is still decreasing. A similar behavior has repeatedly been observed in similarly processed and treated samples. Treatment at a lower temperature of $80^{\circ} \mathrm{C}$, on the other hand, has resulted in a significant rise of $J_{0}$ in accordance with SRD [12]. Values of $J_{0}$ of the [-p-] sample in Fig. 5 might be unreliable after prolonged treatment as will be discussed later on and values after $100 \mathrm{~h}$ are therefore shown in grey.

The $\left[\mathrm{p}^{+} \mathrm{pp}^{+}\right]$sample generally features reduced values of $\tau_{\text {eff }}$ due to additional recombination in the diffused region. Still, the bulk related minimum I is clearly visible. After regeneration of $\tau_{\mathrm{b}}, \tau_{\mathrm{eff}}$ remains rather stable. For treatment times $>50 \mathrm{~h}, \tau_{\text {eff }}$ increases significantly at lower injection (blue) while decreasing slightly at higher injection (red), leading to only a slight increase of $J_{0}$ by $\sim 3 \mathrm{fA} / \mathrm{cm}^{2}$ which lies within the measurement uncertainty. It can be concluded that a diffused region offers fairly stable passivation quality in $\left.\mathrm{ap}^{+} \mathrm{pp}^{+}\right]$structure as well. 

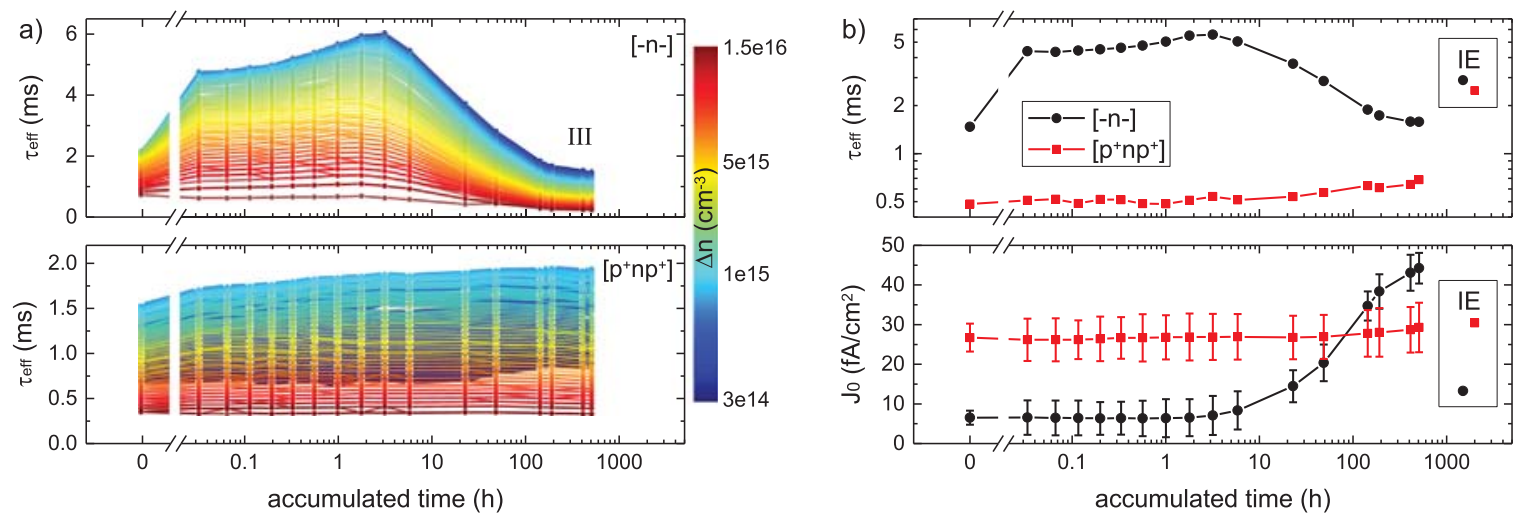

Fig. 4. (a) Injection resolved measurement of $\tau_{\text {eff }}$ of P-doped samples with and without B-emitter during treatment at $150{ }^{\circ} \mathrm{C}$ and $\sim 1$ sun equivalent illumination. (b) Measurement of $\tau_{\text {eff }}\left(\Delta n=0.1 N_{\mathrm{d}}\right)$ and calculated values of $J_{0}$ of the same samples. Values after etching and re-passivation are shown in the "IE" boxes.

Re-passivation of the [-p-] and $\left[\mathrm{p}^{+} \mathrm{pp}^{+}\right]$samples after treatment and removal of $\mathrm{p}^{+}$layers results in rather low $\tau_{\text {eff }} \approx 600 \mu$ s at $\Delta n=0.1$ $N_{\mathrm{d}}$ in both samples ("IE" boxes in Fig. 5). Thus, $\tau_{\text {eff }}$ and $J_{0}$ have deteriorated in the [-p-] sample after re-passivation compared to the degraded sample state. However, the $\left[\mathrm{p}^{+} \mathrm{pp}^{+}\right]$sample features a very similar lifetime and injection dependency after removal of $\mathrm{p}^{+}$layers and re-passivation. It is therefore assumed that both samples are limited by the iodine ethanol passivation and that $\tau_{\mathrm{b}}$ is not significantly different in both samples. Differences in the long-term behavior between both samples in Fig. 5 are thus very likely a consequence of different SRD.

To further analyze SRD, another [-p-] sample was investigated with CC and CV because the sample shown in Fig. 5 had already been repassivated. The other [-p-] sample had received a treatment at $80^{\circ} \mathrm{C}$ and 1 sun for $\sim 2500 \mathrm{~h}$ (shown in [35]) resulting in slight SRD already at the "initial" CC and CV measurements in Table 2. The sample was then treated at $150^{\circ} \mathrm{C}$ and 1 sun for $\sim 460 \mathrm{~h}$, leading to significant SRD comparable to the sample shown in Fig. 5. Contrary to (-p-) samples, the chemical passivation quality of the [-p-] sample does not decrease but increases significantly during this treatment. However, $Q_{\mathrm{f}}$ drops by $\geq 68 \%$ rel on both sample sides in the same timeframe. These results indicate that the temporal evolution of $\mathrm{AlO}_{\mathrm{x}}: \mathrm{H} / \mathrm{SiN}_{\mathrm{x}}: \mathrm{H}$ passivated samples may arise from a mixture of changes in chemical passivation quality and $Q_{\mathrm{f}}$. The long-term SRD at $150{ }^{\circ} \mathrm{C}$ and 1 sun appears to be mainly caused by loss of $Q_{\mathrm{f}}$ in the [-p-] sample, suggesting that SRD of $\mathrm{AlO}_{\mathrm{x}}: \mathrm{H} / \mathrm{SiN}_{\mathrm{x}}: \mathrm{H}$ passivated samples is at least in part based on a different mechanism compared to SRD of $\mathrm{SiN}_{\mathrm{x}}: \mathrm{H}$ passivated samples. The observation that both sample sides show a similar loss in $Q_{\mathrm{f}}$ and previous observations of accelerated SRD under illumination compared to darkness [10] suggest that SRD of [-p-] samples is carrier-induced.

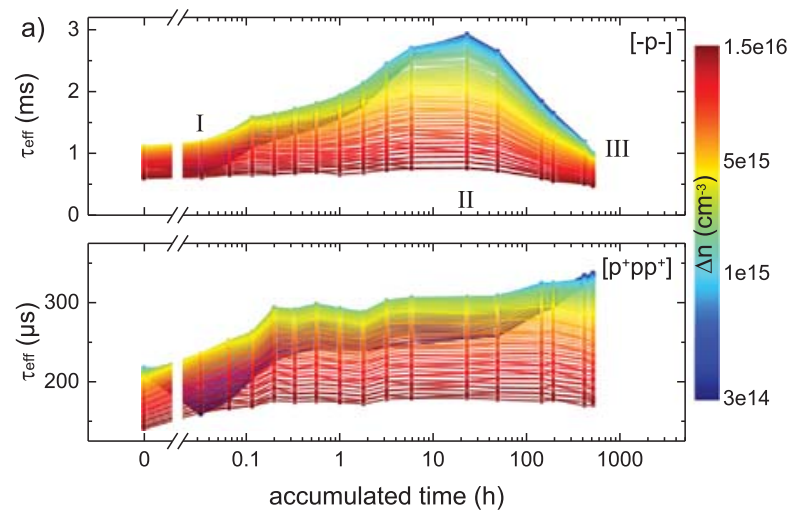

Table 2

$\tau_{\text {eff }}$ before $\left(\tau_{\text {noCC }}\right)$ and after $\left(\tau_{\mathrm{CC}}\right)$ corona charging of front or rear side as well as measured $Q_{\mathrm{f}}$ before ("Initial") and after ("Final") LID treatment.

\begin{tabular}{llllll}
\hline Sample & Side & $\begin{array}{l}\text { Initial } \tau_{\mathrm{CC}} \\
\left(\tau_{\text {noCC }}[\mu \mathrm{s}]^{\mathrm{a}}\right.\end{array}$ & $\begin{array}{l}\text { Final } \tau_{\mathrm{CC}}\left(\tau_{\text {noCC }}\right) \\
{[\mu \mathrm{s}]}\end{array}$ & $\begin{array}{l}\text { Initial } Q_{\mathrm{f}} \\
{\left[\mathrm{q} / \mathrm{cm}^{2}\right]^{\mathrm{a}}}\end{array}$ & $\begin{array}{l}\text { Final } Q_{\mathrm{f}} \\
{\left[\mathrm{q} / \mathrm{cm}^{2}\right]}\end{array}$ \\
\hline$[-\mathrm{p}-]^{\mathrm{a}}$ & Front & $143(1830)$ & $\geq 300(710)$ & $-3.6 \cdot 10^{12}$ & $-8 \cdot 10^{11}$ \\
{$[-\mathrm{p}]^{\mathrm{a}}$} & Rear & $136(1830)$ & $\geq 260(710)$ & $-2.5 \cdot 10^{12}$ & $-8 \cdot 10^{11}$ \\
{$[-\mathrm{n}-]^{\mathrm{b}}$} & Rear & & & $-3.9 \cdot 10^{12}$ & $-1.9 \cdot 10^{12}$ \\
\hline
\end{tabular}

${ }^{a}$ Initial values were measured on a [-p-] sample after $\sim 2500 \mathrm{~h}$ of treatment at $80^{\circ} \mathrm{C}$ and 1 sun; final values were measured on the same sample after treatment at $1500^{\circ} \mathrm{C}$ and 1 sun for $460 \mathrm{~h}$.

${ }^{b}$ Initial values were measured on an untreated [-n-] sample; final values were measured at the end of treatment of the [-n-] sample shown in Fig. 4.

Similar to the [-p-] sample, the comparison of an untreated and treated [-n-] sample in Table 2 shows a significant loss of $Q_{\mathrm{f}}(\sim 50 \%$ rel $)$. As the treated sample was re-passivated directly after treatment, it was not possible to conduct CC measurements on this sample anymore.

\subsection{Device simulations}

It has been shown that $\mathrm{SiN}_{\mathrm{x}}: \mathrm{H}$ related passivation schemes on nondiffused $\mathrm{Si}$ are prone to SRD in accordance with results presented in [10-12]. The degradation is, however, strongly suppressed in samples with a diffused layer below passivation layers. This raises the question whether the degradation mechanism itself is affected or if a sample with emitter is just not sensitive enough so that similar changes at the surface do not translate to a significant change of $\tau_{\text {eff. }}$ To further investigate this question, simulation of an $\left(\mathrm{n}^{+} \mathrm{pn}^{+}\right)$sample was carried

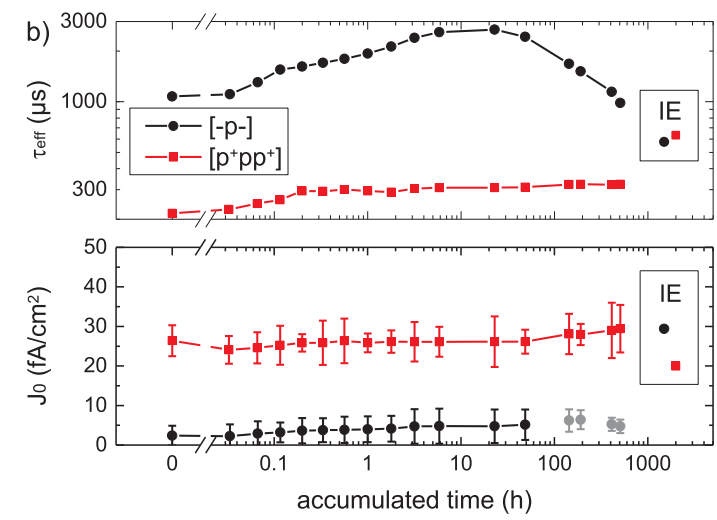

Fig. 5. (a) Injection resolved measurement of $\tau_{\text {eff }}$ of B-doped samples with and without B-emitter during treatment at $150{ }^{\circ} \mathrm{C}$ and $\sim 1$ sun equivalent illumination (color online). (b) Measurement of $\tau_{\text {eff }}\left(\Delta n=0.1 N_{\mathrm{d}}\right.$ ) and calculated values of $J_{0}$ of the same samples. Values after etching and re-passivation are shown in the "IE" boxes. Determined $J_{0}$ values of the [-p-] sample are shown in grey beyond $100 \mathrm{~h}$ of treatment as they are assumed to be unreliable. 
out using the software EDNA 2 [36] which is able to calculate $J_{0}$ from given doping profiles, $S$ and $Q_{\mathrm{f}}$ values.

The general approach is to first assume a similar degradation at the sample surface (same degradation of $S$ ) in samples with $\left(\mathrm{n}^{+} \mathrm{pn}^{+}\right)$and without diffused layers (-p-). The simulation then yields an expected rise $\Delta J_{0}$ for the $\left(\mathrm{n}^{+} \mathrm{pn}^{+}\right)$sample which can be compared to the measured increase. If simulation and measurement coincide, the lower impact of SRD on diffused samples is merely a consequence of reduced sensitivity to the same physical degradation process at the surface. If, however, the simulation yields a higher increase of $J_{0}$ than measured, the degradation mechanism either must have been changed in presence of diffused layers or is not appropriately described with an increase in $S$.

For the simulation, several parameters are needed. Doping profiles stem from ECV profiling as shown in Fig. 2. $Q_{\mathrm{f}}$ was set to $+3.5 \cdot 10^{12} q /$ $\mathrm{cm}^{2}$ as measured at the sample rear side in Table 1 . To achieve simulated values of $J_{0}$ similar to those measured in the $\left(\mathrm{n}^{+} \mathrm{pn}^{+}\right)$sample before sample treatment, an additional SRH recombination had to be added to the emitter, representing recombination, e.g., due to inactive $\mathrm{P}$ [37] or surface-near damage induced by sample processing [38].

Using these parameters, the dependency of $J_{0}$ on $S$ has been calculated and is shown in Fig. 6 (black data). While $J_{0}$ of a sample without emitter is only determined by surface related recombination (dash-dotted line), the $\left(\mathrm{n}^{+} \mathrm{pn}^{+}\right)$sample (solid line) has a lowered sensitivity to changes in $S$ due to additional Auger and SRH recombination, as long as $S$ is small.

The relevant range of $S$ values is determined as follows: $J_{0}$ values of the (-p-) sample without emitter are assumed to arise from degradation at the surface only and therefore equal $J_{0 \mathrm{~s}}$ as discussed in Section 1. Eq. (1) therefore allows to convert measured $J_{0}$ and $Q_{\mathrm{f}}$ of the (-p-) sample to $S$ values before and after degradation as shown in Table 3. Assuming similar degradation $\Delta S$ in the $\left(\mathrm{n}^{+} \mathrm{pn}^{+}\right)$sample, it can be deduced from Fig. 6 that changes in this range (red arrow) would result in a rise of $J_{0}$ by $\sim 25 \mathrm{fA} / \mathrm{cm}^{2}$. Even without additional SRH recombination in the emitter, the simulated rise of $J_{0}$ remains similar. Measured values increase, however, by only $\sim 8 \mathrm{fA} / \mathrm{cm}^{2}$.

One possibility to explain the observed difference between simulated and measured values would be a different $Q_{\mathrm{f}}$ in samples with diffusion. However, $Q_{\mathrm{f}}$ would have to increase significantly (to $\sim 1.5 \cdot 10^{13} \mathrm{q} / \mathrm{cm}^{2}$ ) to explain the observed behavior. If $Q_{\mathrm{f}}$ is similar in (-p-) and $\left(\mathrm{n}^{+} \mathrm{pn}^{+}\right)$samples, the difference in simulated and measured values implies that an emitter changes not only the sensitivity to degradation of $S$ but has further implications for the SRD mechanism as will be discussed in the next section.

Concerning $\mathrm{AlO}_{\mathrm{x}}: \mathrm{H} / \mathrm{SiN}_{\mathrm{x}}: \mathrm{H}$ passivated samples, a simulation with PC1Dmod 6.2 [39] indicates that the measured loss in $Q_{\mathrm{f}}$ is largely able

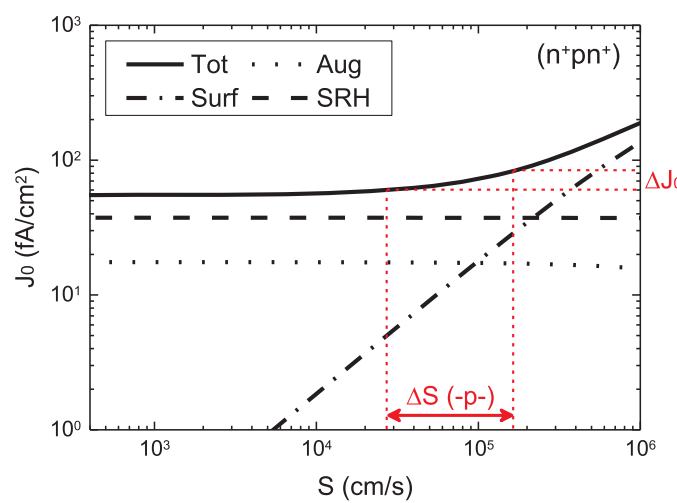

Fig. 6. Simulation of $J_{0}$ of an $\left(\mathrm{n}^{+} \mathrm{pn}^{+}\right)$sample in dependence of $S$. Shown are different components contributing to total (Tot) recombination: Auger (Aug), Surface (Surf) and Shockley-Read-Hall (SRH). The red arrow indicates $S$ values reached by a (-p-) sample before and after degradation (see Table 3 ) and allows to deduce an expected increase $\Delta J_{0}$ for the $\left(\mathrm{n}^{+} \mathrm{pn}^{+}\right)$sample under the assumption of similar $Q_{\mathrm{f}}$ and degradation of $S$.
Table 3

Parameters of the (-p-) sample shown in Fig. 3 before ("Initial") and after ("Final") LID treatment and at point of maximal SRD ("Degraded"). $S$ is calculated according to Eq. (1).

\begin{tabular}{lllllll}
\hline Sample & $\begin{array}{l}\text { Initial } Q_{\mathrm{f}} \\
{\left[\mathrm{q} / \mathrm{cm}^{2}\right]}\end{array}$ & $\begin{array}{l}\text { Final } Q_{\mathrm{f}} \\
{\left[\mathrm{q} / \mathrm{cm}^{2}\right]}\end{array}$ & $\begin{array}{l}\text { Initial } J_{0} \\
{\left[\mathrm{fA} / \mathrm{cm}^{2}\right]}\end{array}$ & $\begin{array}{l}\text { Degraded } J_{0} \\
{\left[\mathrm{fA} / \mathrm{cm}^{2}\right]}\end{array}$ & $\begin{array}{l}\text { Initial } S \\
{[\mathrm{~cm} / \mathrm{s}]}\end{array}$ & $\begin{array}{l}\text { Degraded } \\
S[\mathrm{~cm} / \mathrm{s}]\end{array}$ \\
\hline$(-\mathrm{p}-)$ & $+3.5 \cdot 10^{12}$ & $+3.5 \cdot 10^{12}$ & 10 & 65 & $2.7 \cdot 10^{4}$ & $1.7 \cdot 10^{5}$ \\
\hline
\end{tabular}

to explain degradation of $\tau_{\text {eff }}$ and increase of $J_{0}$ of the [-n-] sample in Fig. 4: Assuming stable $S=3 \cdot 10^{4} \mathrm{~cm} / \mathrm{s}$ at an initial $Q_{\mathrm{f}}=-3.9 \cdot 10^{12}$ $\mathrm{q} \mathrm{cm}{ }^{-2}$ and final $Q_{\mathrm{f}}=-1.9 \cdot 10^{12} \mathrm{q} \mathrm{cm}^{-2}$ (Table 2) results in a simu-

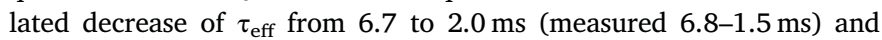
corresponds to an increase of $J_{0}$ from $7.9 \mathrm{fA} / \mathrm{cm}^{2}$ to $33.3 \mathrm{fA} / \mathrm{cm}^{2}$ (measured $\sim 7 \mathrm{fA} / \mathrm{cm}^{2}$ to $\sim 44 \mathrm{fA} / \mathrm{cm}^{2}$ ) according to Eq. (1).

Simulation of $J_{0}$ similar to Fig. 6 is difficult for B-diffused samples as the rather large uncertainty of measured $J_{0}$ in non-diffused samples makes it hard to determine unambiguous simulation parameters. It is, however, noteworthy that a $J_{0}$ simulation of $\left[\mathrm{p}^{+} \mathrm{np}^{+}\right]$samples requires either significantly reduced values of $S$ or significantly increased $Q_{f}$ compared to those of the [-n-] sample to explain the measured low values of $J_{0}$ in the order of $30 \mathrm{fA} / \mathrm{cm}^{2}$ with a doping profile as shown in Fig. 2. The disappearance of measurable SRD furthermore requires either improved stability of $Q_{\mathrm{f}}$ or significantly lowered $S$ (which would make a sample less sensitive towards changes in $Q_{\mathrm{f}}$ ).

\section{Discussion}

\subsection{Mechanisms and root causes of SRD}

For non-diffused samples it was shown that LID treatments at $150{ }^{\circ} \mathrm{C}$ and 1 sun may lead to significant SRD in both $\mathrm{SiN}_{\mathrm{x}}: \mathrm{H}$ and $\mathrm{AlO}_{\mathrm{x}}: \mathrm{H}$ / $\mathrm{SiN}_{\mathrm{x}}: \mathrm{H}$ passivated samples. While a decrease in chemical passivation quality is correlated with $\mathrm{SRD}$ in $\mathrm{SiN}_{\mathrm{x}}: \mathrm{H}$ passivated samples in agreement with previous results [11], the chemical passivation quality appears to even increase in $\mathrm{AlO}_{\mathrm{x}}: \mathrm{H} / \mathrm{SiN}_{\mathrm{x}}: \mathrm{H}$ passivated [-p-] samples after prolonged treatment. However, a significant loss of $Q_{\mathrm{f}}$ was measured in $\mathrm{AlO}_{\mathrm{x}}: \mathrm{H} / \mathrm{SiN}_{\mathrm{x}}: \mathrm{H}$ passivated samples after long-term treatment which leads to a reduced field effect passivation of the surface and is able to explain the observed long-term SRD of $\tau_{\text {eff. Accordingly and contrary to }}$ previous assumptions, the mechanism of SRD appears to differ significantly in $\mathrm{SiN}_{\mathrm{x}}: \mathrm{H}$ and $\mathrm{AlO}_{\mathrm{x}}: \mathrm{H} / \mathrm{SiN}_{\mathrm{x}}: \mathrm{H}$ passivated samples.

As an additional consequence of lower $Q_{\mathrm{f}}$ in [-p-] samples after degradation, the band bending at the surface is weakened and for low $Q_{\mathrm{f}}$, extraction of $J_{0}$ might not work anymore. It appears furthermore possible that illumination might change charge states of interfacial defects temporarily and thus, $Q_{\mathrm{f}}$ might be different during a PCD measurement compared to a CV measurement in darkness. Another possible reason for a failing $J_{0}$ analysis would be a degraded region close to but not directly at the surface which would be less and less shielded by decreasing $Q_{\mathrm{f}}$. This might result in increasing bulk recombination which could then distort the extraction of $J_{0}$ values.

Other studies have investigated a potential degradation of surface passivation quality under varying treatments as well. Two studies observed not a decline but an increase of $Q_{\mathrm{f}}$ caused by illumination of $\mathrm{AlO}_{\mathrm{x}}$ [40] and $\mathrm{AlO}_{\mathrm{x}}: \mathrm{H} / \mathrm{SiN}_{\mathrm{x}}: \mathrm{H}$ [41] passivation. Samples were, however, illuminated less than $100 \mathrm{~h}$ at room temperature and the increase of $Q_{\mathrm{f}}$ was only observed on the illuminated side of samples in [41]. Furthermore, several studies report on UV-induced degradation of different passivation layers, e.g. [42,43], which again only affects the illuminated side of a sample. As SRD affects both sample sides in a similar manner, we assume that the aforementioned effects are rather not related to long-term SRD as observed here. Another study looked at the stability of $\mathrm{AlO}_{\mathrm{x}}: \mathrm{H} / \mathrm{SiN}_{\mathrm{x}}: \mathrm{H}$ passivation and observed a rather weak degradation 
after $\sim 4000 \mathrm{~h}$ of halogen lamp illumination at $75^{\circ} \mathrm{C}$ [44]. This is in good agreement with our observation of only slight degradation of a [-p-] sample treated at $80^{\circ} \mathrm{C}$ and 1 sun as shown in [35]. SRD at these lower temperatures is, however, far away from saturation after $\sim 4000 \mathrm{~h}$ and we would expect those samples to show stronger degradation after continued treatment.

\subsection{Influence of diffused layers on $S R D$}

Diffused layers underneath the passivation layers were shown to reduce $\mathrm{SRD}$ significantly in both $\mathrm{SiN}_{\mathrm{x}}: \mathrm{H}$ and $\mathrm{AlO}_{\mathrm{x}}: \mathrm{H} / \mathrm{SiN}_{\mathrm{x}}: \mathrm{H}$ passivated samples. Assuming similar $Q_{\mathrm{f}}$ and degradation of $S$ in $\operatorname{SiN}_{\mathrm{x}}: \mathrm{H}$ passivated samples with and without diffused surfaces leads to a discrepancy of simulated $\left(\sim 25 \mathrm{fA} / \mathrm{cm}^{2}\right)$ and measured $\left(\sim 8 \mathrm{fA} / \mathrm{cm}^{2}\right)$ increase of $J_{0}$. This discrepancy does, however, vanish if $Q_{\mathrm{f}}$ is increased significantly in diffused samples. Another possible explanation for the difference in simulated and measured $J_{0}$ is degradation in a region around the interface which might not be described accurately by the physical parameter $S$. This appears, however, unlikely because removal of only a few nanometers of the surface and subsequent re-passivation was able to recover samples from SRD in an earlier study [11]. The simulation results therefore indicate either significantly increased $Q_{\mathrm{f}}$ or less defect formation (smaller increase of $S$ ) in the presence of $\mathrm{n}^{+}$diffused silicon surfaces.

According to [12], it can be speculated that hydrogen may be involved in SRD in samples with $\mathrm{SiN}_{\mathrm{x}}$ :H passivation as SRD is most pronounced after a fast firing step which increases the amount of hydrogen in the interface region. Furthermore, it is known that defects at the interface are influenced by processing conditions and might be (partly) passivated with hydrogen after fast firing [38]. However, hydrogen may migrate away from the interface during LID treatment, which would in turn increase recombination. Additionally, it is known that hydrogen platelets can form close to the silicon surface and act as defects [45]. If such hydrogen platelets were to be involved in SRD, it appears possible that a diffused region influences their formation. E.g., more sinks for hydrogen are present in a diffused layer in the form of B$\mathrm{H}$ or P-H bonds. Besides hydrogen, diffusion of another species to the interface may lead to degradation of chemical passivation quality as well. If this species were to originate from the dielectric, it would have to be present in $\mathrm{SiN}_{\mathrm{x}}: \mathrm{H}$ layers made with three different PECVD tools [12] in different locations. One possibility is a contamination of precursor gases commonly used, such as $\mathrm{SiH}_{4}$ and $\mathrm{NH}_{3}$. The contamination could also occur inside of the PECVD tool, e.g., in metallic supply pipes. Such impurities could be gettered in a diffused layer, which could, in turn, prevent degradation.

In $\left[\mathrm{p}^{+} \mathrm{pp}^{+}\right]$and $\left[\mathrm{p}^{+} \mathrm{np}^{+}\right]$samples the almost complete disappearance of SRD could indicate either much more stable $Q_{\mathrm{f}}$ or significantly reduced $S$ induced by $\mathrm{p}^{+}$layers below $\mathrm{AlO}_{\mathrm{x}}: \mathrm{H} / \mathrm{SiN}_{\mathrm{x}}: \mathrm{H}$ passivation. Furthermore, a potential degraded region close to the surface would be more efficiently shielded by a diffused $\mathrm{p}^{+}$region compared to samples without diffused layers.

In general, charge carrier concentrations at the surface under illumination differ by around one order of magnitude in samples with and without diffused layer according to PC1Dmod 6.2 simulations and a change in carrier concentrations might have an influence on fixed charge or defect formation. Another difference between diffused and non-diffused samples is a different temperature load during sample processing. Samples investigated in [12] received, however, a similar high temperature step due to thermal oxidation at $900{ }^{\circ} \mathrm{C}$ and still show severe SRD, so it appears that a high temperature step alone does not prevent SRD.

\subsection{Implications of reduced SRD in diffused samples}

The general finding that diffused surfaces are less prone to SRD of $\tau_{\text {eff }}$ is of use for long-term studies aimed at changes in the silicon bulk.
Since both $J_{0}$ and $\tau_{\mathrm{b}}$ determine the measured $\tau_{\text {eff }}$, a stable surface passivation makes it possible to reliably track changes in $\tau_{\mathrm{b}}$ as discussed in more detail in [35] which investigates the long-term bulk stability of regenerated FZ- and Cz-Si samples. When using diffused surfaces there is, however, a trade-off in the form of lower sensitivity to changes in $\tau_{\mathrm{b}}$ due to additional recombination in a diffused region. E.g., if $\tau_{\mathrm{b}}$ were to degrade from $2 \mathrm{~ms}$ to $1.8 \mathrm{~ms}$ in the $\left(\mathrm{n}^{+} \mathrm{pn}^{+}\right)$sample, this would only lead to a $\sim 2 \mu$ s change in $\tau_{\text {eff. }}$. Accordingly, it should be tried to find a good compromise in a diffusion which has to be sufficiently strong to prevent SRD but should otherwise be as weak as possible to yield high sensitivity to changes in $\tau_{\mathrm{b}}$. In this regard, a lightly B-diffused layer with $\mathrm{AlO}_{\mathrm{x}}: \mathrm{H} / \mathrm{SiN}_{\mathrm{x}}: \mathrm{H}$ passivation appears to be a promising passivation both in terms of stability and passivation quality.

With regard to solar cells, the finding that diffused surfaces are less prone to SRD is good news for cell concepts relying on diffused surfaces only, such as passivated emitter rear totally diffused cells (PERT) [14]. However, in PERC cell concepts with dielectric passivation on lowly doped silicon surfaces, it should be checked whether SRD might affect cell efficiency in the long term. First evidence suggests that SRD might indeed affect PERC solar cells with $\mathrm{SiO}_{\mathrm{x}} / \mathrm{SiN}_{\mathrm{x}}$ : $\mathrm{H}$ rear surface passivation [46].

\section{Conclusions}

In agreement with previously published results, it has been shown that dielectric passivation on lowly doped crystalline silicon can be affected by significant surface related degradation (SRD). Additional measurements have revealed that this degradation affects both front and rear side of a sample in a similar manner and is likely a carrier induced effect. While SRD is caused by a loss of chemical passivation quality in $\mathrm{SiN}_{\mathrm{x}}: \mathrm{H}$ passivated samples, $\mathrm{AlO}_{\mathrm{x}}: \mathrm{H} / \mathrm{SiN}_{\mathrm{x}}: \mathrm{H}$ passivated samples mainly degrade due to a loss of $Q_{\mathrm{f}}$. SRD is, however, strongly attenuated on highly doped silicon surfaces resulting from either P- or Bdiffusion. Device simulations indicate that the enhanced passivation stability arises not only due to decreased sensitivity of diffused samples towards changes at the surface but requires further differences between diffused and non-diffused samples or changes in the degradation mechanism. The enhanced stability of diffused surfaces is of use for light induced degradation studies and solar cell concepts relying on diffused surfaces on both sample sides like PERT.

\section{Acknowledgements}

The authors would like to thank J. Lindroos and C. Derricks for help with wet-chemical re-passivation, A. Graf for continued support with data analysis, and L. Mahlstaedt, F. Mutter, S. Joos, B. Rettenmaier and J. Engelhardt for technical support.

\section{Funding}

Part of this work was supported by the German Federal Ministry for Economic Affairs and Energy [grant numbers 0325763B, 0324001]. The authors are responsible for the content.

\section{Declarations of interest}

None.

\section{References}

[1] K. Ramspeck, S. Zimmermann, H. Nagel, A. Metz, Y. Gassenbauer, B. Birkmann, A. Seidl, Light induced degradation of rear passivated mc-Si solar cells, Proc 27th Eur. Photovoltaic Sol. Energy Conf. Exhib., Frankfurt/Main, Germany, 861-865.

[2] F. Fertig, K. Krauß, S. Rein, Light-induced degradation of PECVD aluminium oxide passivated silicon solar cells, Phys. Status Solidi RRL 9 (2015) 41-46.

[3] F. Kersten, P. Engelhart, H.C. Ploigt, A. Stekolnikov, T. Lindner, F. Stenzel, J.W. Müller, Degradation of multicrystalline silicon solar cells and modules after 
illumination at elevated temperature, Sol. Energ. Mater. Sol. Cells 142 (2015) 83-86.

[4] F. Fertig, et al., Mass production of p-type Cz silicon solar cells approaching average stable conversion efficiencies of 22\%, Energy Proc. 124 (2017) 338-345.

[5] T. Niewelt, F. Schindler, W. Kwapil, R. Eberle, J. Schön, M.C. Schubert, Understanding the light-induced degradation at elevated temperatures: similarities between multicrystalline and floatzone p-type silicon, Prog. Photovolt.: Res. Appl. 26 (2018) 533-542.

[6] H. Fischer, W. Pschunder, Investigation of photon and thermal induced changes in silicon solar cells, Proc. 10th IEEE Photovolt. Spec. Conf. Rec., Palo Alto, CA, USA, 1974, 404-411.

[7] K. Bothe, J. Schmidt, Electronically activated boron-oxygen-related recombination centers in crystalline silicon, J. Appl. Phys. 99 (2006) 13701.

[8] T. Niewelt, J. Schön, W. Warta, S.W. Glunz, M.C. Schubert, Degradation of crystalline silicon due to boron-oxygen defects, IEEE J. Photovolt. 7 (2017) 383-398.

[9] R.S. Bonilla, B. Hoex, P. Hamer, P.R. Wilshaw, Dielectric surface passivation for silicon solar cells: a review, Phys. Status Solidi A 214 (2017) 1700293.

[10] D. Sperber, A. Herguth, G. Hahn, Instability of dielectric surface passivation quality at elevated temperature and illumination, Energy Proc. 92 (2016) 211-217.

[11] D. Sperber, A. Heilemann, A. Herguth, G. Hahn, Temperature and light induced changes in bulk and passivation quality of boron-doped float-zone silicon coated with $\mathrm{SiN}_{\mathrm{x}}: \mathrm{H}$, IEEE J. Photovolt. 7 (2017) 463-470.

[12] D. Sperber, A. Graf, D. Skorka, A. Herguth, G. Hahn, Degradation of surface passivation on crystalline silicon and its impact on light-induced degradation experiments, IEEE J. Photovolt. 7 (2017) 1627-1634.

[13] A.W. Blakers, A. Wang, A.M. Milne, J. Zhao, M.A. Green, $22.8 \%$ efficient silicon solar cell, Appl. Phys. Lett. 55 (1989) 1363-1365.

[14] M.A. Green, The passivated emitter and rear cell (PERC): from conception to mass production, Sol. Energ. Mater. Sol. Cells 143 (2015) 190-197.

[15] T. Dullweber, J. Schmidt, Industrial silicon solar cells applying the passivated emitter and rear cell (PERC) concept - A review, IEEE J. Photovolt. 6 (2016) $1366-1381$.

[16] H. Haverkamp, A. Dastgheib-Shirazi, B. Raabe, F. Book, G. Hahn, Minimizing the electrical losses on the front side: development of a selective emitter process from a single diffusion, Proc. 33rd IEEE Photovolt. Spec. Conf. Rec., San Diego, USA, 430433.

[17] G. Hahn, Status of selective emitter technology, Proc.s 25th Eur. Photovoltaic Sol. Energy Conf. Exhib., Valencia, Spain, 1091-1096.

[18] A. Herguth, On the meaning(fullness) of the intensity unit 'suns' in light induced degradation experiments, Energy Proc. 124 (2017) 53-59.

[19] H. Nagel, C. Berge, A.G. Aberle, Generalized analysis of quasi-steady-state and quasi-transient measurements of carrier lifetimes in semiconductors, J. Appl. Phys. 86 (1999) 6218-6221.

[20] R.A. Sinton, A. Cuevas, M. Stuckings, Quasi-steady-state photoconductance, a new method for solar cell material and device characterization, Proc. 25th IEEE Photovolt. Spec. Conf. Rec., Washington D.C., USA, 1996, 457-460.

[21] A. Kimmerle, J. Greulich, A. Wolf, Carrier-diffusion corrected $J_{0}$-analysis of charge carrier lifetime measurements for increased consistency, Sol. Energ. Mater. Sol. Cells 142 (2015) 116-122.

[22] A.L. Blum, et al., Interlaboratory study of eddy-current measurement of excesscarrier recombination lifetime, IEEE J. Photovolt. 4 (2014) 525-531.

[23] K.R. McIntosh, R.A. Sinton, Uncertainty in photoconductance lifetime measurements that use an inductive-coil detector, Proc. 23rd Eur. Photovoltaic Sol. Energy Conf. Exhib., Valencia, Spain, 77-82.

[24] K.R. McIntosh, L.E. Black, On effective surface recombination parameters, J. Appl. Phys. 116 (2014) 014503.

[25] T. Horanyi, T. Pavelka, P. Tüttö, In situ bulk lifetime measurements on silicon with a chemically passivated surface, Appl. Surf. Sci. 63 (1993) 306-311.

[26] A.W. Stephens, M.A. Green, Effectiveness of $0.08 \mathrm{M}$ iodine in ethanol solution as a means of chemical surface passivation for photoconductance decay measurements, Sol. Energ. Mater. Sol. Cells 45 (1997) 255-265.

[27] K.L. Pollock, J. Junge, G. Hahn, Detailed investigation of surface passivation methods for lifetime measurements on p-type silicon wafers, IEEE J. Photovolt. 2 (2012) 1-6.

[28] N.E. Grant, J.D. Murphy, Temporary surface passivation for characterisation of bulk defects in silicon: a review, Phys. Status Solidi RRL 11 (2017) 1700243.

[29] D. Sperber, A. Graf, A. Heilemann, A. Herguth, G. Hahn, Bulk and surface instabilities in boron doped float-zone samples during light induced degradation treatments, Energy Proc. 124 (2017) 794-798.

[30] D. Sperber, A. Herguth, G. Hahn, A 3-state defect model for light induced degradation in boron-doped float-zone silicon, Phys. Status Solidi RRL 11 (2017) 1600408.

[31] T. Niewelt, M. Selinger, N.E. Grant, W. Kwapil, J.D. Murphy, M.C. Schubert, Lightinduced activation and deactivation of bulk defects in boron-doped float-zone silicon, J. Appl. Phys. 121 (2017) 185702.

[32] D. Sperber, A. Herguth, G. Hahn, Investigating possible causes of light induced degradation in boron-doped float-zone silicon, Proc. 33rd Eur. Photovoltaic Sol. Energy Conf. Exhib., Amsterdam, The Netherlands, 565-568.

[33] M. Kessler, T. Ohrdes, P.P. Altermatt, R. Brendel, The effect of sample edge recombination on the averaged injection-dependent carrier lifetime in silicon, J. Appl. Phys. 111 (2012) 054508.

[34] B. Veith, T. Ohrdes, F. Werner, R. Brendel, P.P. Altermatt, N.P. Harder, J. Schmidt, Injection dependence of the effective lifetime of n-type $\mathrm{Si}$ passivated by $\mathrm{Al}_{2} \mathrm{O}_{3}$ : an edge effect? Sol. Energ. Mater. Sol. Cells 120 (2014) 436-440.

[35] D. Sperber, A. Herguth, G. Hahn, On improved passivation stability on highly-doped crystalline silicon and the long-term stability of regenerated Cz-Si, Sol. Energy Mater. Sol. Cells 185 (2018) 277-282.

[36] K.R. McIntosh, P.P. Altermatt, A freeware 1D emitter model for silicon solar cells, Proc. 35th IEEE Photovolt. Spec. Conf. Rec., Honolulu, USA, 2188-2193.

[37] A. Dastgheib-Shirazi, A. Peral, M. Steyer, J. Rinder, H. Wagner, G. Hahn, Dissolution of electrically inactive phosphorus by low temperature annealing, Energy Proc. 77 (2015) 286-290.

[38] B. Sopori, Y.I. Zhang, R. Reedy, K. Jones, Y. Yan, M. Jassim, B. Bathey, J. Kalejs, A comprehensive model of hydrogen transport into a solar cell during silicon nitride processing for fire-through metallization, 31st IEEE Photovolt. Spec. Conf. Rec., Lake Buena Vista, USA, 1039-1042.

[39] H. Haug, J. Greulich, PC1Dmod 6.2 - Improved simulation of c-Si devices with updates on device physics and user interface, Energy Proc. 92 (2016) 60-68.

[40] B. Liao, R. Stangl, T. Mueller, F. Lin, C.S. Bhatia, B. Hoex, The effect of light soaking on crystalline silicon surface passivation by atomic layer deposited $\mathrm{Al}_{2} \mathrm{O}_{3}$, J. Appl. Phys. 113 (2013) 024509.

[41] F. Lin, et al., Impacts of light illumination on monocrystalline silicon surfaces passivated by atomic layer deposited $\mathrm{Al}_{2} \mathrm{O}_{3}$ capped with plasma-enhanced chemical vapor deposited $\mathrm{SiN}_{\mathrm{x}}$, Jpn. J. Appl. Phys. 56 (2017) 08MB01.

[42] R. Witteck, B. Veith-Wolf, H. Schulte-Huxel, A. Morlier, M.R. Vogt, M. Köntges, R. Brendel, UV-induced degradation of PERC solar modules with UV-transparent encapsulation materials, Prog. Photovolt. Res. Appl. 25 (2017) 409-416.

[43] B. Veith-Wolf, R. Witteck, A. Morlier, H. Schulte-Huxel, M.R. Vogt, J. Schmidt, Spectra-dependent stability of the passivation quality of $\mathrm{Al}_{2} \mathrm{O}_{3} / \mathrm{c}$-Si interfaces, IEEF J. Photovolt. 8 (2018) 96-102.

[44] T. Niewelt, W. Kwapil, M. Selinger, A. Richter, M.C. Schubert, Long-term stability of aluminum oxide based surface passivation schemes under illumination at elevated temperatures, IEEE J. Photovolt. 7 (2017) 1197-1202.

[45] S.B. Zhang, W.B. Jackson, Formation of extended hydrogen complexes in silicon, Phys. Rev. B 43 (1991) 12142.

[46] A. Herguth, C. Derricks, D. Sperber, A detailed study on light-induced degradation of Cz-Si PERC-Type solar cells: Evidence of rear surface-related degradation, IEEE J. Photovolt. 8 (2018) 1190-1201. 